\title{
ВИВЧЕННЯ ВАЛІДАЦІЙНОГО ПАРАМЕТРА \\ “ЛІНІЙНІСТЬ/КАЛІБРУВАЛЬНА МОДЕЛЬ” АНАЛІТИЧНОЇ МЕТОДИКИ КІЛЬКІСНОГО ВИЗНАЧЕННЯ КАРДІАЗОЛУ В БІОЛОГІЧНИХ РІДИНАХ ДЛЯ ПРОВЕДЕННЯ ФАРМАКОКІНЕТИЧНИХ ДОСЛІДЖЕНЬ
}

Вступ. Одним із найважливіших етапів створення лікарських засобів є доклінічні та клінічні випробування, належне проведення яких гарантує в подальшому безпечність і високу терапевтичну ефективність розроблених лікарських засобів. Ключовим елементом доклінічних досліджень є різноманітні фрармакологічні методики, при застосуванні яких здійснюють ряд аналітичних вимірювань на тих чи інших біологічних об'єктах. Таким чином, набувають актуальності питання, пов'язані з визначенням особливостей процесу валідації біоаналітичних методів, які використовують під час доклінічних фрармакологічних досліджень лікарських засобів та розробки стандартизованих підходів до проведення таких валідаційних робіт для оригінальних субстанцій.

Мета дослідження - провести експериментальне вивчення валідаційного параметра "лінійність/ калібрувальна модель" методики кількісного визначення кардіазолу в плазмі крові для виконання фрармакокінетичних досліджень.

Методи дослідження. Біоаналітична методика визначення кардіазолу ґрунтується на BEPX/MC/ MC-аналізі аналітів у досліджуваних розчинах, отриманих із зразків плазми після попереднього осадження протеїнів. Проби хроматографрують з використанням хроматографрічної колонки Discovery C18 (50×2,1 мм) з розміром часток 5 мкм та градієнтного елюювання.

Результати й обговорення. При побудові калібрувальної кривої необхідно виконати такі умови: для нижньої межі кількісного визначення відхилення від номінальної концентрації повинно бути не більшим \pm 20 \%, для калібрувальних розчинів з концентраціями, вищими, ніж нижня межа кількісного визначення, - не більшим $\pm 15 \%$. Доведено лінійну залежність між концентрацією та площею хроматографрічних піків кардіазолу в діапазоні концентрацій 1-100 нг/мл. Рівняння регресії - y=0,0141x+-0,00146, коефіцієнт кореляuіï $-r^{2}=0,9985$.

Висновок. Висновок щодо розробленої методики стосовно валідаційного параметра "лінійність/калібрувальна модель" - коректна.

КЛЮЧОВІ СЛОВА: кардіазол; валідація; валідаційний параметр “лінійність/калібрувальна модель”; фармакокінетика.

ВСТУП. Фармацевтична розробка, стандартизація і біоаналітичні дослідження ліків включають у себе широкий спектр досліджень вихідних субстанцій, готових лікарських засобів, дослідження in vitro та in vivo тощо. На всіх етапах цих досліджень потрібно використовувати валідовані аналітичні методики. Для того, щоб результати аналізу, отримані на різних етапах, були зіставними, необхідно процедури їх виконання уніфікувати, аналітичні методики застосовувати за одним специфічним методом і валідувати за єдиною стандартизованою процедурою. Дослідження 3 питань валідації доволі добре пред(с I. В. Драпак, 2019. ставлено в наукових працях учених, але аналіз публікацій свідчить про те, що здебільшого порушуються та розкриваються питання валідації біоаналітичних методів визначення різних аналітів у біологічних рідинах. Таким чином, набувають актуальності питання, пов'язані з визначенням особливостей процесу валідації біоаналітичних методів, які використовують під час доклінічних фрармакологічних досліджень лікарських засобів та розробки стандартизованих підходів до проведення таких валідаційних робіт для оригінальних субстанцій [1-6].

Кардіазол (гідробромід [3-алліл-4-(4¹-метоксисреніл)-3Н-тіазол-2-іліден]-(3²-трифрлуоро- 
метилфеніл)аміну) - оригінальний новосинтезований кардіопротектор, який, окрім кардіопротекторної дії, проявляє також гіполіпідемічну, протизапальну, анальгетичну та антиоксидантну активність $[7,8]$. Це вказує на перспективність даної речовини для подальшого доклінічного дослідження.

Мета дослідження - провести експериментальне вивчення валідаційного параметра "лінійність/калібрувальна модель" методики кількісного визначення кардіазолу в плазмі крові для виконання фрармакокінетичних досліджень.

МЕТОДИ ДОСЛІДЖЕННЯ. Об'єктом ДОслідження був кардіазол.

У кожну пробірку вносять по 50 мкл кожного розчину QC-зразків та 50 мкл розчинів кожного внутрішнього стандарту в 450 мкл бланкової плазми. Пробірки закривають та перемішують їх вміст на шейкері протягом 10 с. Вносять 50 мкл розчинів внутрішніх стандартів у 0,5 мл плазми, струшують 4 хв. Осаджують протеїни шляхом додавання 1,5 мл ацетонітрилу та струшування протягом 4 хв, потім центрифругують при 4000 об./хв при $5{ }^{\circ} \mathrm{C}$ упродовж 10 хв. До 1 мл прозорого розчину додають 1 мл води та проводять хроматографування. Проби хроматографують 3 використанням хроматограсрічної колонки Discovery C18 (50×2,1 мм) 3 розміром часток 5 мкм та градієнтного елюювання. Елюент А - ацетонітрил - вода - кислота мурашина $(5: 95: 0,1)$, елюент В - ацетонітрил - кислота мурашина $(100: 0,1)$. Швидкість потоку - 0,4 мл/хв. Температура термостата колонки - $30^{\circ} \mathrm{C}$. Об'єм проби, яку вводять, -4 мкл.

РЕЗУЛЬТАТИ Й ОБГОВОРЕННЯ. БіоаНалітична методика визначення кардіазолу ґрунтується на BEPX/MC/MC-аналізі аналітів у досліджуваних розчинах, отриманих із зразків плазми після попереднього осадження протеїнів. При- датність біоаналітичної методики була підтверджена валідаційними характеристиками, які висувають до біоаналітичних методик [9-11]. У даній роботі описано валідаційний параметр “лінійність/калібрувальна модель". Ми розробили електронні протоколи з використанням Microsoft Excel, в яких передбачено поля для введення даних.

Лінійність - це здатність аналітичної методики (в певному діапазоні застосування) забезпечувати отримання результатів випробувань, прямо пропорційних концентрації (кількості) аналіту в зразку (ICH). Цей параметр наявний в усіх керівництвах, що дають рекомендації щодо валідації біоаналітичних методик. Лінійність калібрувальної кривої оцінюють за калібрувальними стандартами кардіазолу, приготовленими на плазмі крові, використовуючи алгоритм розрахунків параметрів лінійної регресії методом найменших квадратів у системі координат "відношення площ хроматографічних піків аналіту або внутрішнього стандарту до концентрації". Результати вивчення валідаційного параметра "лінійність/калібрувальна модель" методики кількісного визначення кардіазолу в плазмі крові наведено в таблиці. Калібрувальну криву представлено на рисунку.

При побудові калібрувальної кривої потрібно виконати такі умови: для нижньої межі кількісного визначення відхилення від номінальної концентрації повинно бути не більшим $\pm 20 \%$, для калібрувальних розчинів з концентраціями, вищими, ніж нижня межа кількісного визначення, не більшим $\pm 15 \%$. Калібрувальні розчини, відхилення яких становить понад $\pm 15 \%$, слід виключити з розрахунку рівнянь регресії, не змінюючи вихідної моделі.

Доведено лінійну залежність між концентрацією та площею хроматографрічних піків кардіазолу в діапазоні концентрацій 1-100 нг/мл. Рівняння регресії - $\mathrm{y}=0,0141 \mathrm{x}+-0,00146$, коефріцієнт

Таблиця - Результати вивчення валідаційного параметра “лінійність/калібрувальна модель" методики кількісного визначення кардіазолу в плазмі крові

\begin{tabular}{|c|c|c|c|c|}
\hline Розчин & $\begin{array}{c}\text { Площа піка } \\
\text { кардіазолу }\end{array}$ & $\begin{array}{c}\text { Площа піка } \\
\text { внутрішнього } \\
\text { стандарту }\end{array}$ & $\begin{array}{c}\text { Знайдена } \\
\text { концентрація, нг/мл }\end{array}$ & Точність, \% \\
\hline $\mathrm{BI}$ & 68 & 194 & $\mathrm{~N} / \mathrm{A}$ & $\mathrm{N} / \mathrm{A}$ \\
\hline $\mathrm{Z}$ & 73 & 125735 & 0,145 & $\mathrm{~N} / \mathrm{A}$ \\
\hline $\mathrm{C} 1$ & 1964 & 140111 & 1,10 & 95,3 \\
\hline $\mathrm{C} 2$ & 5143 & 132624 & 2,86 & 97,0 \\
\hline $\mathrm{C} 3$ & 18781 & 138965 & 9,70 & 93,6 \\
\hline $\mathrm{C} 4$ & 57713 & 134027 & 30,7 & 95,8 \\
\hline $\mathrm{C} 6$ & 88961 & 135284 & 46,8 & 106,0 \\
\hline $\mathrm{C} 7$ & 139694 & 138236 & 71,9 & $\mathrm{~N} / \mathrm{A}$ \\
\hline $\mathrm{Bl}$ & 202407 & 135821 & 106,0 & $\mathrm{~N} / \mathrm{A}$ \\
\hline $\mathrm{Bl}$ & 1014 & 1367 & $\mathrm{~N} / \mathrm{A}$ & $\mathrm{N} / \mathrm{A}$ \\
\hline
\end{tabular}




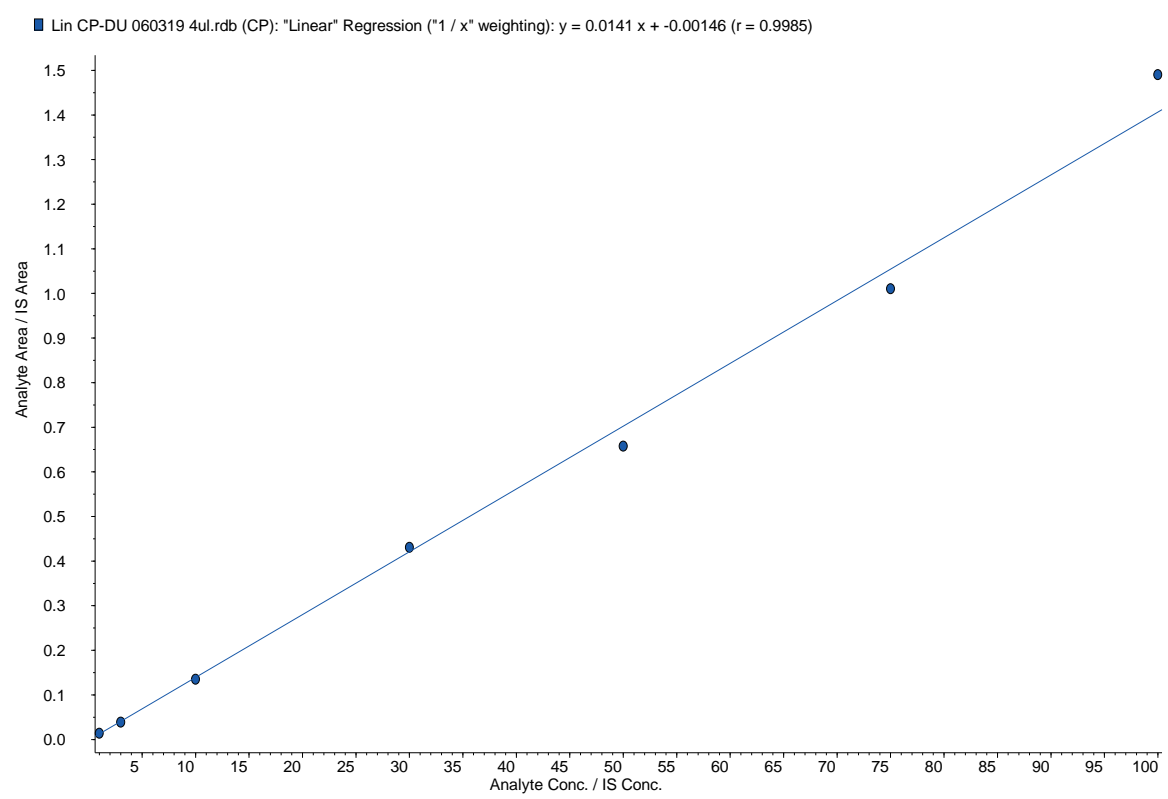

Рис. Калібрувальна крива визначення кардіазолу в плазмі крові.

кореляції - $r^{2}=0,9985$. Висновок щодо розробленої методики стосовно валідаційного параметра “лінійність/калібрувальна модель" - коректна.

ВИСНОВКИ. 1. Вивчено валідаційний параметр “лінійність/калібрувальна модель” методи- ки кількісного визначення кардіазолу в плазмі крові для проведення фрармакокінетичних досліджень.

2. Висновок щодо розробленої методики стосовно валідаційного параметра “лінійність/ калібрувальна модель” - коректна.

\section{СПИСОК ЛІТЕРАТУРИ}

1. A strategy for validation of bioanalytical methods / S. Braggio, R. J. Barnaby, P. Grosi, M. Cugola // Journal of Pharmaceutical and Biomedical Analysis. - 1996. - 14, No. 4. - P. 375-388.

2. Bioanlytical method development and validation / U. K. Singh, P. Pandey, P. K. Keshri // J. Biorg. Chem. 2000. - 2. - P. 34-45.

3. Causon R. Validation of chromatographic methods in biomedical analysis viewpoint and discussion. J. Chromatogr. B. - 1997. - 689, No. 1. - P. 175-180.

4. Sharma A. Bioanalytical Method development and Validation of Drugs in Biological fluid / A. Sharma, S. Rathore // Int. J. of Pharm \& Research Sci. - 2012. - 1, No. 4. - P. 216-226.

5. James C. A. Bioanalytical method validation: a risk-based approach / C. A. James, M. Breda, E. Frigerio / Journal of Pharmaceutical and Biomedical Analysis // 2004. - 35, No. 4. - P. 887-889.

6. Bioanalytical method development and validation by using LC-Ms/Ms / S. Murugan, N. Pravallika, P. Sirisha, K. Chandrakala // Journal of Chemical and Pharmaceutical Sciences. - 2013. - 6, No. 1. - P. 41-45.

7. Synthesis and in silico research of derivatives of 3-allyl-4-(R-phenyl)-N-(R1-phenyl)thiazole-2-imine /
L. O. Perekhoda, I. V. Drapak, M. M. Suleiman [et al.] // Der Pharma Chemica. - 2017. - No. 9 (13). - P. 95-98.

8. Пат. на корисну модель 122197 Україна, МПК C07D 277/42, А61K 31/426, A61P 9/00. Гідробромід [3-аліл-4-(41-метоксифеніл)-3Н-тіазол-2-іліден]-(32трифлуорометилфеніл)аміну, що має кардіопротекторні властивості / Драпак І. В., Перехода Л. О., Демченко А. М., Геращенко І. В., Нєктєгаєв І. О. ; власник Львів. нац. мед. ун-т імені Данила Галицького. - № u 201707267 ; заявл. 10.07.17 ; опубл. 26.12.17, Бюл. 24

9. Валидация биоаналитического метода: метод. рек. / ГП "Государственный экспертный центр". - К., 2013. - 35 c.

10. Logoyda L. The methods for determination of combination antihypertensive drugs in human plasma by HPLC MS/MS / L. Logoyda, D. Korobko, S. Kovalenko // $23^{\text {nd }}$ Dubai International Pharmaceuticals \& Technologies Conference \& Exhibition, February 27 - March 01, 2018. Dubai. - 2018. - P. 40.

11. Guidance for Industry. Bioanalytical Method Validation / Center for Drug Evaluation and Research, U.S. Food and Drug Administration, U.S. Department of Health and Human Services, Rockvill, Maryland, May; 2001. 


\section{REFERENCES}

1. Braggio, S., Barnaby, R.J., Grosi, P., \& Cugola, M. (1996). A strategy for validation of bioanalytical methods. Journal of Pharmaceutical and Biomedical Analysis, 14 (4), 375-388.

2. Singh, U.K., Pandey, P., \& Keshri, P.K. (2000). Bioanlytical method development and validation. Biorg. Chem., 2, 34-45.

3. Causon, R. (1997). Validation of chromatographic methods in biomedical analysis viewpoint and discussion. J. Chromatogr. B., 689 (1), 175-180.

4. Sharma, A., \& Rathore, S. (2012). Bioanalytical Method development and validation of drugs in biological fluid. Int. J. of Pharm \& Research Sci., 1 (4), 216-226.

5. James, C.A., Breda, M., \& Frigerio, E. (2004). Bioanalytical method validation: a risk-based approach. Journal of Pharmaceutical and Biomedical Analysis, 35 (4), 887-889.

6. Murugan, S., Pravallika, N., Sirisha, P., \& Chandrakala, K. (2013). Bioanalytical method development and validation by using LC-MS/MS. Journal of Chemical and Pharmaceutical Sciences, 6 (1), 41-45.

7. Perekhoda, L.O., Drapak, I.V., Suleiman, M.M., Sych, I.A., \& Yaremenko, V.D. (2017). Synthesis and in silico research of derivatives of 3-allyl-4-(R-phenyl)-N(R1-phenyl)thiazole-2-imine. Der Pharma Chemica, 9 (13), 95-98.

8. Drapak, I.V., Perekhoda, L.O, Demchenko, A.M., Herashchenko, I.V., \& Niektiehaiev, I.O. (2017). Patent na korysnu model № 122197 Hidrobromid [3-alil-4-(41metoksyfenil)-3N-tiazol-2-iliden]-(32-tryfluorometylfenil) aminu, shcho maye kardioprotektorni vlastyvosti [Patent for Utility Model No. 122197 Hydrobromide [3-allyl-4(41-methoxyphenyl)-3H-thiazole-2-ylidene]-(32-trifluoromethylphenyl) amine having cardioprotective properties]. Vlasnyk - Lvivskyi natsionalnyi medychnyi universytet imeni Danyla Halytskoho - Patent for Utility Model No. 122197 Hydrobromide [3-allyl-4-(41-methoxyphenyl)-3Hthiazole-2-ylidene]-(32-trifluoromethylphenyl) amine having cardioprotective properties. The owner - Danylo Halytskyi Lviv National Medical University, a statement. 07.10.2017, Published on December 26, 2017-Jul.24 [in Ukrainian].

9. (2013). Validatsiya bioanaliticheskogo metoda: metod. rekomendatsii [Validation of the bioanalytical method: method. recommendations]. Kyiv: "Gosudarstvennyy ekspertnyy tsentr" [in Russian].

10. Logoyda, L., Korobko, D., \& Kovalenko, S. (2018). The methods for determination of combination antihypertensive drugs in human plasma by HPLC MS/MS. $23^{\text {nd }}$ Dubai International Pharmaceuticals \& Technologies Conference \& Exhibition, February, 27 - March, 01, 2018. Dubai.

11. Guidance for Industry. Bioanalytical Method Validation//Center for Drug Evaluation and Research, U.S. Food and Drug Administration, U.S. Department of Health and Human Services, Rockvill, Maryland, May 2001.

\section{ИЗУЧЕНИЕ ВАЛИДАЦИОННОГО ПАРАМЕТРА “ЛИНЕЙНОСТЬ/КАЛИБРОВОЧНАЯ МОДЕЛЬ” АНАЛИТИЧЕСКОЙ МЕТОДИКИ КОЛИЧЕСТВЕННОГО ОПРЕДЕЛЕНИЯ КАРДИАЗОЛА В БИОЛОГИЧЕСКИХ ЖИДКОСТЯХ ДЛЯ ПРОВЕДЕНИЯ ФАРМАКОКИНЕТИЧЕСКИХ ИССЛЕДОВАНИЙ}

Резюме

Вступление. Одним из важнейших этапов создания лекарственных средств являются доклинические и клинические испытания, надлежащее проведение которых гарантирует в дальнейшем безопасность и высокую терапевтическую эфрфрективность разработанных лекарственных средств. Ключевым элементом доклинических исследований являются различные фрармакологические методики, при применении которых осуществляют ряд аналитических измерений на тех или иных биологических объектах. Таким образом, приобретают актуальность вопросы, связанные с определением особенностей процесса валидации биоаналитических методов, которые используют во время доклинических фрармакологических исследований лекарственных средств и разработки стандартизированных подходов к проведению таких валидационных работ для оригинальных субстанций.

Цель исследования - провести экспериментальное изучение валидационного параметра "линейность/калибровочная модель" методики количественного определения кардиазола в плазме крови для выполнения фрармакокинетических исследований.

Методы исследования. Биоаналитическая методика определения кардиазола основывается на ВЭЖХ/МС/MC-анализе аналитов в исследуемых растворах, полученных из образцов плазмы после предварительного осаждения протеинов. Пробы хроматографируют с использованием хроматографической колонки Discovery C18 (50×2,1 мм) с размером частиц 5 мкм и градиентного элюирования. 
Результаты и обсуждение. При построении калибровочной кривой необходимо выполнить следующие условия: для нижнего предела количественного определения отклонение от номинальной концентрации должно быть не более \pm 20 \%, для калибровочных растворов с концентрациями, которые превышают нижний предел количественного определения, - не более $\pm 15 \%$. Доказана линейная зависимость между концентрацией и площадью хроматографических пиков кардиазола в диапазоне концентраций 1-100 нг/мл. Уравнение регрессии - y=0,0141x+-0,00146, коэфрфициент корреляции - $r^{2}=0,9985$.

Вывод. Вывод по разработанной методике относительно валидационного параметра “линейность/ калибровочная модель" - корректна.

КЛЮЧЕВЫЕ СЛОВА: кардиазол; валидация; валидационный параметр “линейность/калибровочная модель"; фрармакокинетика.

DANYLO HALYTSKYI LVIV NATIONAL MEDICAL UNIVERSITY

\section{STUDY OF THE VALIDATION PARAMETER “LINEARITY/CALIBRATION MODEL” OF ANALYTICAL METHODOLOGY OF QUANTITATIVE DETERMINATION OF KARDIAZOL IN BIOLOGICAL LIQUIDS FOR PHARMACOKINETIC STUDIES}

\section{Summary}

Introduction. Preclinical and clinical trials are one of the most important stages in the development of medicinal products, the proper conduct of which ensures in the future the safety and high therapeutic effectiveness of the developed medicines. A key element of preclinical research is a variety of pharmacological methods, in which a number of analytical measurements are carried out on certain biological objects. Thus, issues related to the identification of the peculiarities of the validation process of bioanalytical methods used in preclinical pharmacological research of medicinal products and the development of standardized approaches to such validation work for original substances become relevant.

The aim of the study - to make an experimental study of the validation parameter "linearity/calibration model" for quantitative determination of Kardiazol in human plasma for pharmacokinetic studies.

Research Methods. The bioanalytical method for the determination of Kardiazol is based on HPLC/MS/MS analysis of analytes in investigated solutions obtained from plasma samples after pre-precipitation of proteins. Samples were chromatographed using Discovery C18 chromatography column, $50 \times 2.1 \mathrm{~mm}$, with a particle size of $5 \mu \mathrm{m}$ and gradient elution.

Results and Discussion. When constructing a calibration curve, the following conditions must be fulfilled: for lower limit of quantitative determination, the deviation from the nominal concentration should be no more than $\pm 20 \%$; for calibration solutions with concentrations more than lower limit of quantitative determination, the deviation from the nominal concentration should be no more than $\pm 15 \%$. A linear relationship was found between the concentration and the area of the chromatographic peaks of cardiogenol in the concentration range of $1 \mathrm{ng} / \mathrm{ml}-100 \mathrm{ng} / \mathrm{ml}$. The regression equation is $y=0.0141 x+-0.00146$, the correlation coefficient is $r^{2}=0.9985$.

Conclusion. The conclusion regarding the developed methodology according to the validation parameter "linearity/calibration model" is correct.

KEY WORDS: Kardiazol; validation; “linearity/calibration model”, pharmacokinetics.

Отримано 29.01.19

Адреса для листування: І. В. Драпак, Львівський національний медичний університет імені Данила Галицького, вул. Пекарська, 69, Львів, 79010, Україна, e-mail: iradrapak@ukr.net. 